\title{
Contribution of cardiac pacing to our understanding of the Wolff-Parkinson-White syndrome
}

\author{
Hein J. J. Wellens \\ From the University Department of Cardiology, Wilhelmina Gasthuis, Amsterdam, The Netherlands
}

This review discusses the information which can be obtained by cardiac pacing in patients with the WolffParkinson-White syndrome. Programmed electrical stimulation when combined with the recording of intracardiac electrograms and surface electrocardiograph leads, can be extremely useful in the following areas. I) Determining the type of the accessory atrioventricular connexions; 2) determining the electrophysiological properties of the accessory atrioventricular pathway; 3) localizing the position of the accessory atrioventricular pathway; 4) determining the mechanisms of any tachycardia; 5) assessing effect of drugs; 6) identifying patients likely to be at high risk; and 7) evaluating postoperative conduction.

The introduction of epicardial mapping (Durrer and Roos, 1967) and programmed electrical stimulation of the heart (Durrer et al., 1967) into clinical cardiology has resulted in a better understanding of the Wolff-Parkinson-White (WPW) syndrome and its therapy. Our opinions on the value and limitations of epicardial excitation mapping have recently been published (Wellens et al., 1974a). The purpose of the present article is to review information which can be obtained by programmed electrical stimulation of the heart in patients with the WPW syndrome and to consider its uses. The techniques of programmed electrical stimulation will first be described and the possible substrates for ventricular pre-excitation will then be reviewed. Thereafter the way in which it is possible to locate the position of an accessory pathway and determine its electrophysiological properties, how the mechanism of tachycardia can be elucidated, how it is possible to study the effect of drugs on pre-excitation and how patients at high risk may be identified, and finally how programmed electrical stimulation may be used for postoperative evaluation will be described.

\section{Technique}

Programmed electrical stimulation of the heart demands the use of electrode catheters and a stimulator. The catheter, preferably a bipolar one, is inserted, usually by means of the Seldinger technique, into either a femoral or an antecubital vein. The tip of the catheter is positioned, under fluoroscopic control, at the desired intracardiac location and connected with the stimulator. Care must be taken that the stimulator is electrically safe for the patient (Starmer, Whalen, and McIntosh, I964; Burchell and Sturm, 1967) and accurate. It should have the capabilities of providing the following (Wellens (1971)): I) regular pacing of the heart at different frequencies; 2) an extra stimulus at any desired interval during regular pacing and following any desired number of paced beats (the 'single test stimulus' method); and 3) the possibility of insertion of a stimulus at any desired moment in the cardiac cycle during a spontaneous rhythm.

It is necessary to record a His bundle electrogram (Scherlag et al., 1969), an intracavitary right atrial lead, and at least two extremity leads and two praecordial leads. If anatomical localization of the accessory pathway is necessary (e.g. to allow subsequent surgical interruption of the bypass), then either a left atrial endocavitary electrogram or a recording from the coronary sinus should also be registered.

\section{Anatomical substrates for pre-excitation}

In pre-excitation, apart from the usual AV pathway, extra atrioventricular connexions are thought to be present. If one starts from the concept that the AV junction can be divided into an AV node (composed of the compact node and a zone of transitional cells), a penetrating part of the AV bundle, a branching part of the AV bundle, and the bundlebranches (Hecht et al., 1973; Anderson et al., 1975b), 

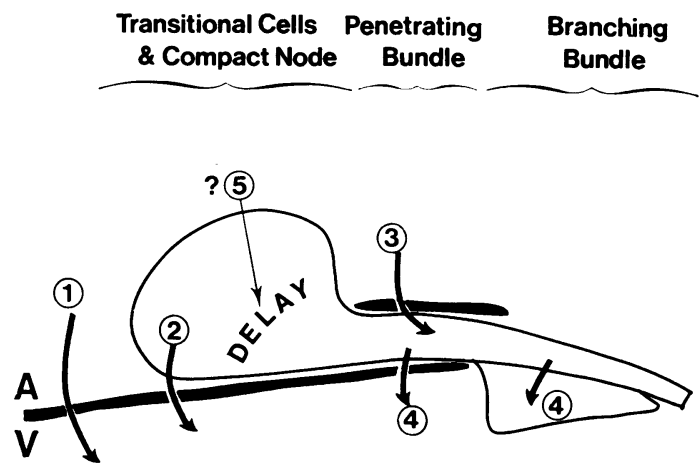

FIG. I Classification and nomenclature of ventricular pre-excitation by the European Study Group for Pre-excitation (Anderson et al., 1975a). I) Direct connexion between atrium and ventricle: accessory atrioventricular pathway; 2) Connexion between the $A V$ node and the ventricle: nodoventricular fibre; 3) Connexion between atrium and $A V$ bundle (bundle of His): atriofascicular tract (falls in the group of AV nodal bypass tracts); 4) Connexion between the penetrating (left) or the branching part of the $A V$ bundle (right) and the ventricle: fasciculoventricular fibres; 5) Short circuit in the AV node itself (falls in the group of AV nodal bypass tracts).

these accessory connexions can be divided (classification of the European Study Group for Preexcitation, Anderson et al., 1975a) (Fig. I) into the following. I) Accessory atrioventricular pathways forming a direct connexion between atrium and ventricle (classical Wolff-Parkinson-White (WPW) syndrome); 2) nodoventricular accessory connexions: fibres connecting the AV node with ventricular myocardium; 3) fasciculoventricular accessory connexions: fibres connecting the penetrating part or the branching part of the AV bundle (bundle of His) with ventricular myocardium; 4) $A V$ nodal bypass tracts: either pathways connecting the atrium with the penetrating part of the AV bundle termed atriofascicular bypass tracts or short circuits within the AV node itself.

The expected electrocardiographic patterns accompanying these connexions would be as follows. A) accessory atrioventricular pathway (classical WPW): a PR interval of 0.I2 s or less, a delta wave, and a QRS width of $0.12 \mathrm{~s}$ or more. B) Nodoventricular and fasciculoventricular accessory connexions: a PR interval of more than $0.12 \mathrm{~s}$, a small delta wave, and a QRS width of less than 0.I2 s. The length of the PR interval and the width of the delta wave and the QRS depending upon the site of take-off of the fibre. C) $A V$ nodal bypass tract: a PR interval of
$0.12 \mathrm{~s}$ or less and a normal QRS complex. The finding of accessory AV muscle bundles, previously called Kent bundles, has been reported by several authors (see Anderson et al., 1975a). Nodoventricular and fasciculoventricular fibres have been described anatomically by Mahaim and Winston (194I), Lev et al. (1966), and Anderson et al. (1974). AV nodal bypass tracts of the atriofascicular variety have been described by Brechenmacher $e t a l$. (1974), while James (1963) described intranodal bypass routes.

In the absence of studies which correlate anatomical with electrophysiological findings many inconsistencies exist between the anatomical presence and electrophysiological significance of these accessory connexions. Based upon our speculations as to how connexions in these locations should behave electrophysiologically, one would expect the following changes during electrical stimulation of the different types of accessory connexions.

\section{A) An accessory atrioventricular pathway}

When the single test stimulus method is used during atrial pacing, increase in prematurity of the test pulse results in an increase in area of the ventricle activated via the bypass. This is because the AV nodal transmission time (the AH interval) increases with increasing prematurity of the given atrial premature beat while conduction through the bypass (the atrium to delta interval) stays constant. As pointed out by Castellanos et al. (1970), during this type of stimulation the His bundle electrogram, which signals impulse transmission over the AV node-His pathway characteristically comes progressively later after the beginning of ventricular activation via the bypass. The localization of the $\mathrm{His}$ bundle electrogram relative to the beginning of the delta wave during sinus rhythm and basic driving of the atrium will depend upon: a) AV nodal transmission time, itself influenced by the rate-dependant electrophysiological properties of the AV node; b) the distance between site of impulse formation in the atrium and atrial end of the bypass tract; c) conduction velocity in the bypass (probably related to the thickness of the bypass); and d) the length of the bypass. From this it immediately follows that an accessory atrioventricular pathway (and therefore a WPW syndrome) can exist in the absence of the classical WPW criteria on the standard electrocardiogram. For example the $\mathbf{P}$ delta interval may be more than $0.12 \mathrm{~s}$ if the atrial end of the bypass is activated late (localization in the left atrium or because of intraatrial conduction delay) or the QRS duration may be less than $0.12 \mathrm{~s}$ if pre-excitation of the ventricle starts late in relation to ventricular activation through the 
AV node-His axis (Slama, Coumel, and Bouvrain, 1973).

\section{B) Nodoventricular and fasciculoventricular accessory connexions}

The changes in QRS complex configuration after test stimuli given with increasing prematurity will depend upon the level of take-off of the bypass fibres from the specific conducting tissue of the AV junction. In contrast to an accessory AV pathway the impulse on its way from atrium to ventricle has to traverse some AV nodal tissue. Therefore, there will be some increase in atrium due to delta interval after atrial test stimuli given with increasing prematurity. The more proximal the point of take-off from the AV node the greater the area of AV nodal delay which is short circuited and the greater the amount of pre-excitation. On theoretical grounds a fibre taking off from the AV node at such a location that the greater portion of the delay-producing area is bypassed can result in an electrocardiogram indistinguishable from that produced by an accessory AV pathway. They can be differentiated, however, by comparing QRS configuration during right and left atrial pacing (vide infra).

Accessory connexions taking origin from the AV (bundle of His) can theoretically be recognized by the presence of short HV intervals (shorter than $30 \mathrm{~ms})$. The configuration of the QRS complex will depend upon the site of ventricular insertion of the pathway and the difference in time between onset of ventricular excitation over the fasciculoventricular fibres and over the normal intraventricular conduction system.

\section{C) AV nodal bypass tract}

Because the AV node is short circuited, after atrial test stimuli given with increasing prematurity the AH interval should characteristically be short. Increase in AV nodal transmission time (AH interval) should not occur up to the refractory period of the bypass. As pointed out by Castellanos et al. (1971), Mandel, Danzig, and Hayakawa (1971), Caracta et al. (1973), Bissett et al. (1973), and Denes, Wu, and Rosen (1974) this is a rare finding. Electrical stimulation studies using the single test stimulus method have shown that many patients with short PR intervals (0.12 s or less) and normal QRS complexes who were considered to be examples of an AV nodal bypass tract do in fact show an increase in AV nodal transmission time. Caracta et al. (1973) postulated that in some of these patients the AV node might be anatomically small. Mandel et al. (I97I) suggested the possibility of a short circuit within the AV node itself. Though one would theoretically expect the HV interval to be normal in these patients both Mandel et al. (1971) and Denes et al. (1974) noted them to be shorter than $30 \mathrm{~ms}$. This raised the question as to the presence of other bypass tracts in these patients.

It has been shown by Coumel et al. (1972) that more than one bypass tract can exist in the same heart, a state of affairs which obviously complicates the study and treatment of these patients. Both Josephson, Caracta, and Lau (1974) and Spurrell, Krikler, and Sowton (1975) showed that both rightand left-sided pathways could be operative in the same patient. Furthermore it was suggested by Spurrell et al. (1975) that during tachycardia a different accessory pathway was used than that during AV conduction in sinus rhythm or atrial pacing.

\section{Electrophysiological properties of the accessory AV pathway}

In contrast to the AV node, where the effective refractory period (defined as the shortest atrial premature beat interval followed by conduction through the AV node) lengthens with increasing driving rates, the effective refractory period of the bypass usually shortens with increased driving rates. This is important because it indicates that while the AV node becomes more effective as far as protecting the ventricle against high atrial rate is concerned, the accessory pathway might lack this effect of protection against increase in heart rate. As stated earlier, a true AV bypass tract is not characterized by lengthening of the atrium to delta interval following atrial test stimuli given with increasing prematurity. When AV conduction is stressed in patients with the WPW syndrome by pacing the atrium at increasing rates, the differences in pattern of conduction through the node and through the accessory pathway can be demonstrated by registering the sequence of different degrees of AV block in the two pathways (Table $\mathrm{I}$ ).

TABLE I Sequence of different degrees of $A V$ block in accessory atrioventricular pathway and $A V$ node

\begin{tabular}{ll}
\hline Accessory pathway & AV node \\
\hline & Ist degree block \\
& $\downarrow$ \\
Mobitz II block & Wenckebach type 2nd degree block \\
$\downarrow$ & $\downarrow$ \\
2 to r block & 2 to I block \\
$\downarrow$ & $\downarrow$ \\
Complete block & Complete block \\
\hline
\end{tabular}


Examples of Mobitz II block in the accessory pathway and Wenckebach type block in the AV node have been reported (Roelandt et al., 1973; Wellens and Durrer, 1973b).

Very rarely Wenckebach type conduction delay can be observed in the accessory pathway. We have observed two such examples in 92 patients with WPW in whom stimulation studies were performed (Wellens and Durrer, 1973b). It is essential to exclude intra-atrial conduction delay, which might mimic this phenomenon (Castellanos et al., 1972; Narula, Runge, and Samet, 1972).

By using the single test stimulus method during ventricular pacing, patterns of ventriculoatrial (VA) conduction can also be studied (Wellens and Durrer, 1974a). The following patterns of VA conduction in the WPW syndrome can be recognized; I) conduction via the accessory pathway (AP) only; 2) conduction by both the AP and the His-AV nodal (H-AV) pathway, with either a) the AP having the shortest refractory period, b) the $\mathrm{H}-\mathrm{AV}$ pathway having the shortest refractory period, or c) with identical refractory periods for both pathways. In the last situation, because of the shorter time interval required for passage of the impulse through the $\mathrm{AP}$, it will be impossible to distinguish this pattern from the first; 3) conduction via the $\mathrm{H}-\mathrm{AV}$ pathway only; 4) absence of VA conduction (both the AP and the H-AV pathway being blocked).

In our series the most common pattern of VA conduction found was the one characterized by no significant change in VA conduction time following test stimuli given with increasing prematurity (6I out of 92 patients). This pattern suggests either exclusive VA conduction by way of the accessory pathway, conduction through an accessory pathway with a shorter refractory period than the H-AV node pathway, or identical refractory periods in both pathways. It is of interest to note that 8 of 92 patients who showed AV conduction over both pathways during atrial pacing had no VA conduction over either pathway during ventricular pacing! An example of a progressive increase in VA conduction time over the AV nodal pathway followed by reentry over the accessory pathway is shown in Fig. 2.

Fig. 3 compares the length of the refractory period of the accessory pathway during ventricular stimulation with that obtained during atrial stimulation. In order to make this comparison it is necessary firstly that the basic frequency of both ventricular and atrial pacing during which test stimuli were
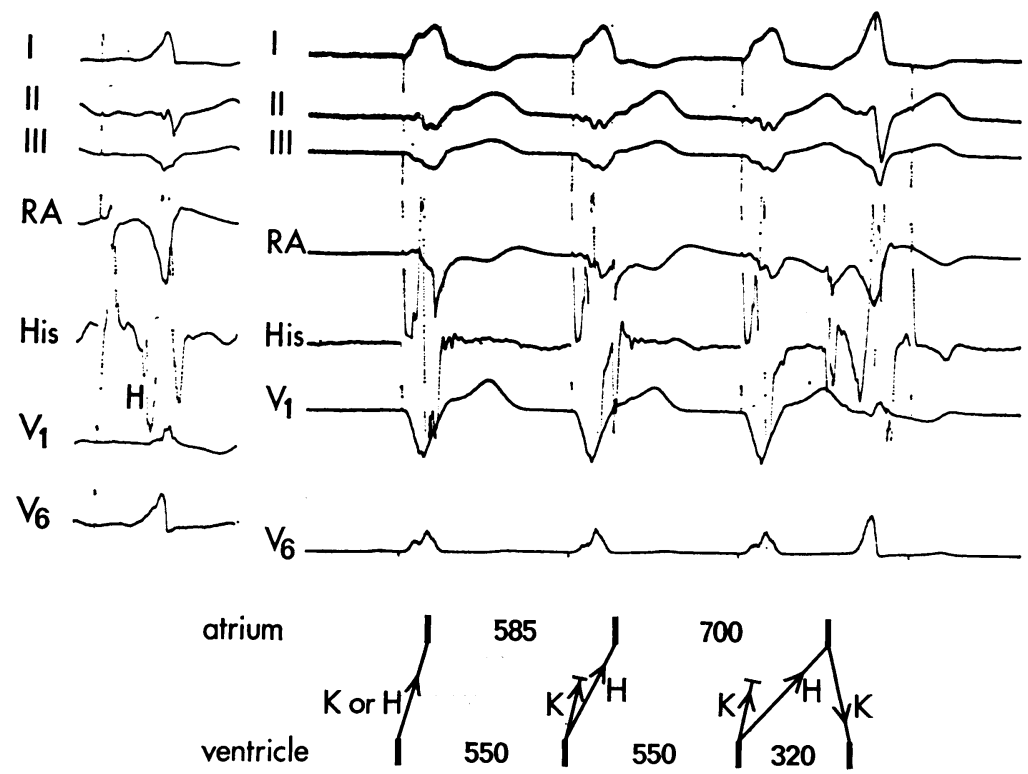

FIG. $2 V A$ conduction during regular pacing of the ventricle showing gradual increase in VA conduction time followed by a QRS complex with Wolff-Parkinson-White configuration. As explained in the diagram, $V A$ conduction over the His- $A V$ node pathway is assumed to be followed (at a critical VA interval) by re-excitation of the ventricle over the accessory $A V$ pathway. $K=$ accessory $A V$ pathway, $H=H i s-A V$ node pathway. 


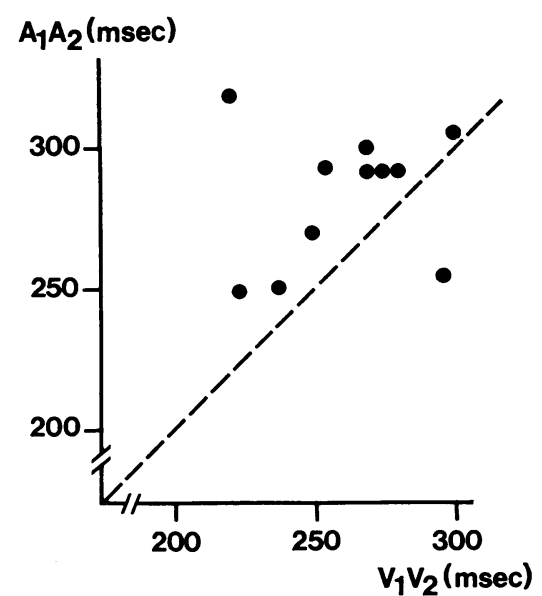

FIG. 3 Comparison of the effective refractory period of the accessory $A V$ pathway as determined by the single test stimulus method during atrial and ventricular pacing at identical pacing frequencies. Note that in 10 of the II patients the refractory period in $V A$ direction was shorter than in $A V$ direction.

applied was the same; and secondly that the refractory period of the right atrium and the right ventricle was shorter than that of the accessory pathway. As shown in Fig. 3, ro of the II patients showed a shorter refractory period of the bypass during ventricular pacing. The possible explanations of this phenomenon are discussed elsewhere (Wellens and Durrer, 1974a).

\section{Localization of the accessory AV pathway}

Rosenbaum et al. (1945) classified the electrocardiograms of patients with the WPW syndrome according to the form of the ventricular complex in praecordial leads. Type $\mathbf{A}$ was characterized by an $\mathbf{R}$ wave as the sole, or by far the largest, deflection in leads VI, V2, and Ve, and type B an S or QS as the chief QRS deflection in one of leads VI, V2, and Ve. In patients with type A WPW, early activation of the left ventricle has been demonstrated by epicardial mapping (Boineau et al., 1973; Wallace et al., 1974; Wellens et al., 1974a) and ablation of pre-excitation followed left-sided surgery (Wallace et al., 1974; Wellens et al., 1974a). In patients with type B WPW, early ventricular activation has been found on the lateral and posterior aspect of the right ventricle (Durrer and Roos, 1967; Burchell et al., 1967; Boineau et al., 1973) and the right side of the interventricular septum (Svenson et al., 1974). One of the problems in trying to correlate the electrocardiographic pattern with the site of ventricular insertion of the bypass is that the electrocardiogram represents a fusion complex between

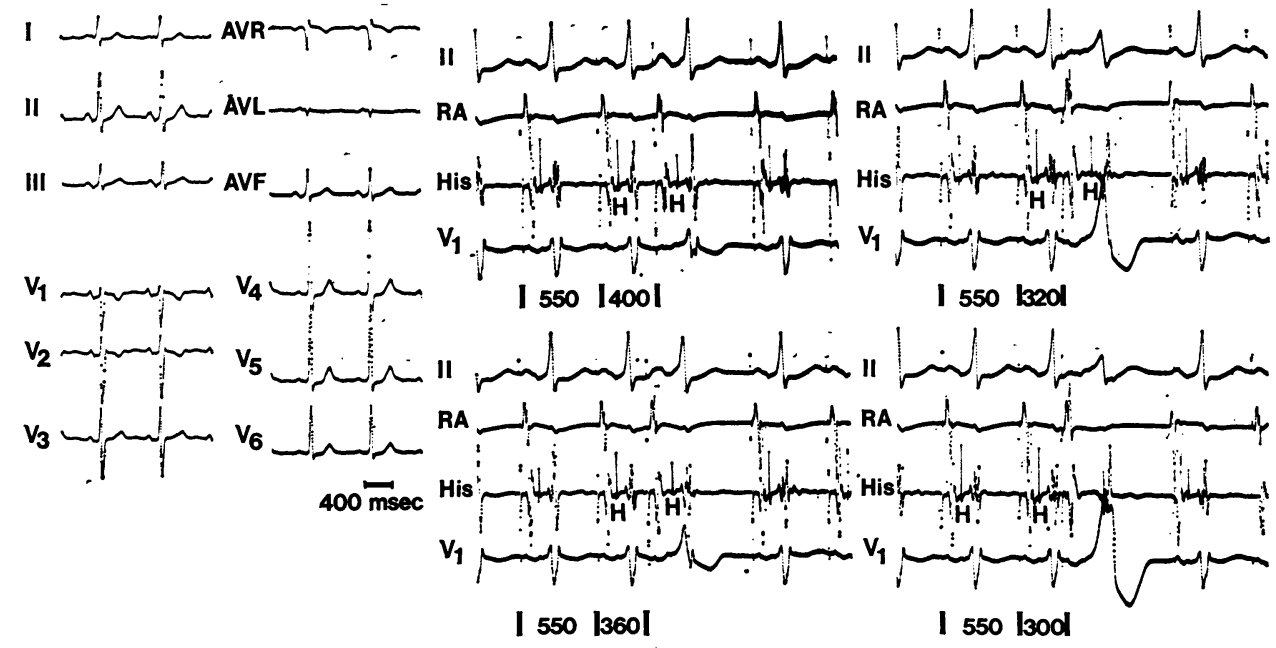

FIG. 4 Value of programmed electrical stimulation for classification of WPW. The electrocardiogram on the left shows pre-excitation with a $Q R S$ configuration which would have to be classified as type BWPW according to the criteria of Rosenbaum et al. (1945). During atrial pacing the introduction of test stimuli with increasing prematurity clearly demonstrates, however, that left-sided (type A) WPW was present in this patient. 
ventricular excitation over the AV nodal-His pathway and the accessory pathway. When the contribution to ventricular excitation through the accessory pathway is small the ventricular complex may differ little from normal. This situation frequently prevents predictions concerning the most likely site of the ventricular insertion of the bypass (Slama et al., 1973; Durrer and Wellens, 1974). It is illustrated in Fig. 4. During basic driving the demonstrated electrocardiogram would be classified as showing WPW type B. By giving atrial premature beats with increasing prematurity, leading to an increasingly larger ventricular area being excited over the accessory pathway, it becomes clear that type A WPW is present. By using both the single test stimulus method during atrial pacing and by pacing the atrium at increasing rates, the augmentation of the area of pre-excitation will facilitate recognition of the most likely location of the bypass. When atrial pacing is performed close to the bypass, the pre-excited area will be larger than during pacing far away from the bypass (Wellens, Schuilenburg, and Durrer, 197I; Touboul et al., 1972). An example of this situation is given in Fig. 5 . Comparison of the effect of right and left atrial pacing on QRS configuration should also be helpful in differentiating between an accessory AV pathway and a nodoventricular accessory connexion which short circuits an important part of the delay producing area of the AV node. In the former QRS complex configuration will differ during right and left atrial pacing at identical pacing rates. In contrast, such differences would not be observed in the latter situation because an area of $\mathrm{AV}$ nodal tissue precedes the accessory connexion.

Recording right and left atrial (either from the left atrial cavity or from the coronary sinus) activation simultaneously during ventricular pacing to produce retrograde conduction can give information on the location of the atrial end of the bypass. This should preferably be combined by recording atrial activation from the His bundle lead in the vicinity of the AV node. Left atrial activation which precedes actrial activation low on the interatrial septum and in the right atrium is a strong argument in favour of a left atrial origin of the bypass (Zipes, DeJoseph, and Rothbaum, 1974; Svenson et al., 1974; Wellens and Durrer, 1974d).

When left and right atrial activation are recorded during tachycardia simultaneously with low right atrial activation in the His bundle lead, it is frequently possible to determine whether the accessory pathway is incorporated in the tachycardia circuit (Wellens and Durrer, 1974d).

\section{Mechanisms of tachycardia}

As postulated by Holzmann and Scherf (1932) and Wolferth and Wood (1933) the presence of two pathways between atrium and ventricle produces the theoretical possibility of a circus movement tachycardia utilizing $\mathrm{AV}$ conduction over one pathway and VA conduction over the other pathway. A premature beat together with different electrophysiological properties of the two pathways are essential for the initiation of such a tachycardia. In order for
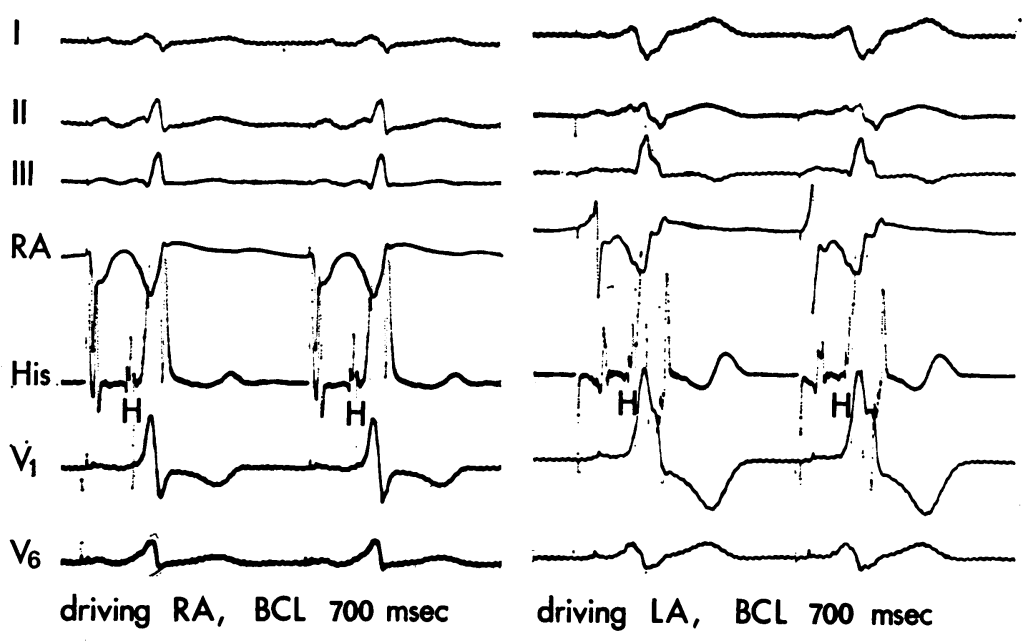

FIG. 5 QRS configuration during right and left atrial pacing at identical pacing frequencies in a patient with left-sided pre-excitation. Note that ventricular excitation over the accessory $A V$ pathway is much greater during left than during right atrial pacing. 
the tachycardia to be perpetuated, it is necessary for the tachycardia pathway length to be longer than the product of mean conduction velocity of the circulating impulse and the mean refractory period of the tachycardia pathway (Mines, 1913). Durrer et al. (1967) validated these postulated theories by using programmed electrical stimulation of the heart in patients with the WPW syndrome. They were able to demonstrate that during atrial pacing a critically timed atrial premature beat was blocked in the accessory pathway and exclusively conducted to the ventricle over the AV node. After activation of the ventricle, re-excitation of the atrium occurred over the accessory pathway. If this movement was perpetuated, then tachycardia resulted. A similar type of tachycardia could be initiated by an appropriately timed ventricular premature beat during ventricular pacing. Tachycardias could not only be initiated by critically timed premature beat but also terminated by a similar procedure. The explanation of this phenomenon was considered to be the creation of a zone of refractoriness in the tachycardia pathway upon which the circulating impulse collided. The most common type of circus movement tachycardia which can be initiated by a premature beat is the one showing AV conduction via the AV node. Tachycardias with AV conduction over the accessory pathway are rare (Grolleau et al., 1970; Wellens, I971; Zipes et al., 1974; Wellens and
Durrer, 1974a). Apart from the single premature beat creating refractoriness in one of the two AV pathways, other mechanisms for initiation of tachycardia have been identified, such as an atrial (Wellens, 197I) or ventricular echo beat (Fig. 6). It has also been shown that in patients with the WPW syndrome the accessory pathway does not have to be incorporated in the tachycardia circuit but that the arrhythmia can be confined to the atrium (Fig. 7), the AV node (Wellens and Durrer, 1974d), or the ventricle (Wellens et al., 1974b). Methods of establishing the presence or absence of the accessory pathway in the tachycardia circuit have been given elsewhere (Coumel and Attuel, 1974; Wellens and Durrer, 1974d). Identification of the location of the tachycardia circuit becomes mandatory if surgical interruption is being considered. Knowledge of its location is also helpful in selecting the appropriate drug for treatment of tachycardia (see below). Lastly, its identification is important if treatment of drug-resistant tachycardia by chronic electrical stimulation is contemplated. This is because the success of the method is influenced by the proximity of the site of stimulation to the tachycardia circuit (Wellens, 1971).

\section{Effect of drugs}

Programmed electrical stimulation provides the possibility of studying directly the effect of drugs

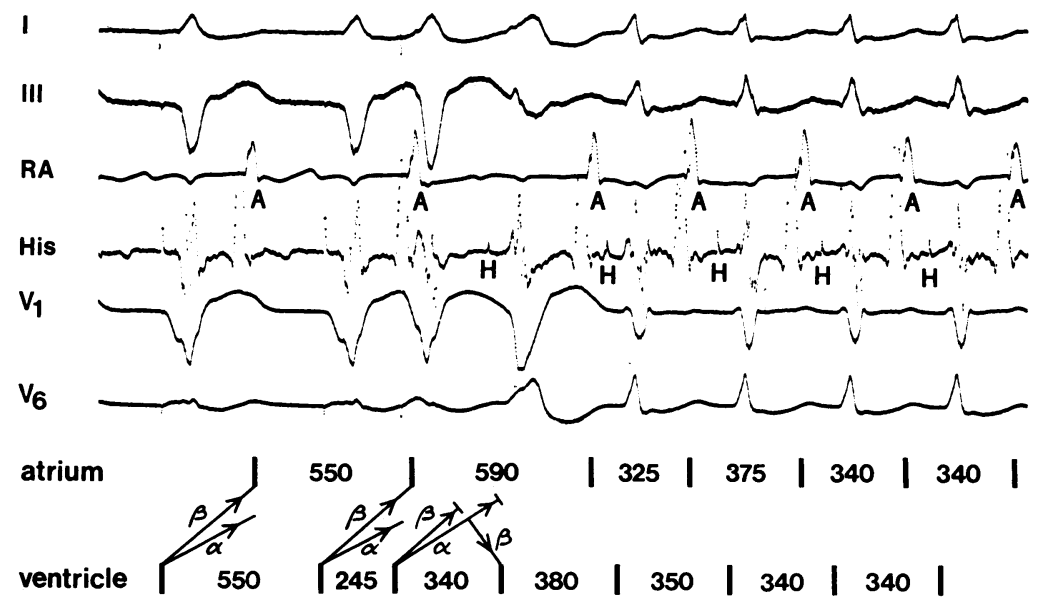

FIG. 6 Initiation of tachycardia by a ventricular echo beat during ventricular pacing. Note that the QRS complex which follows the premature beat given after $245 \mathrm{~ms}$ is preceded by a His bundle complex at the same $H V$ interval as the QRS complexes, during tachycardia. This ventricular complex is thought to be the result of longitudinal dissociation in the $A V$ node (see diagram) leading to re-excitation of the ventricle with left aberrant conduction. From this type of initiation of tachycardia we cannot conclude whether during tachycardia an accessory AV pathway is used or that perpetuation of re-entry in the $A V$ node is responsible for the tachycardia. 

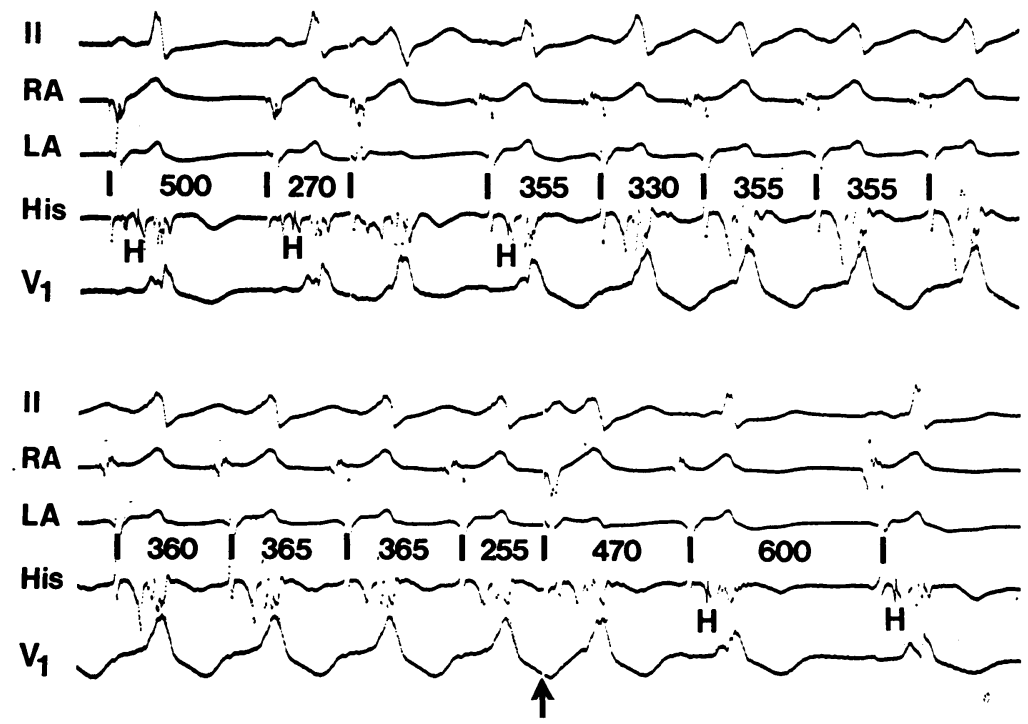

FIG. 7 Atrial tachycardia in a patient with the WPW syndrome. Top: initiation of tachycardia by an atrial premature beat during pacing of the atrial septum. Note that during tachycardia high right atrial activation precedes low right atrial activation (in the His bundle lead) and left atrial activation Bottom: Termination of tachycardia by a single atrial premature beat. The sinus beats following termination of tachycardia show the same sequence of atrial activation as during tachycardia, indicating that the site of origin of the tachycardia is high in the right atrium. This could be an example of an atrial tachycardia based upon re-entry in the region of the sinus node.

on the electrophysiological properties of the two atrioventricular pathways and on the mechanisms of tachycardia in patients with the WPW syndrome.

For these measurements pacing frequencies before and after drug administration should be the same. Stimulating and recording electrode catheters should also stay in the same intracardiac location. Table 2 lists the effect of different drugs on the refractory periods of the AV node and the accessory pathway and on the HV interval. Drug treatment of symptomatic patients with WPW syndrome should be preceded by: I) identification and treatment of congenital or acquired heart disease which might provoke or exacerbate an arrhythmia; 2) identification of the type of arrhythmia present (circus movement tachycardia, atrial fibrillation, atrial flutter,

TABLE 2 Effect of drugs on refractory period of accessory pathway and $A V$ node and on $H V$ interval

\begin{tabular}{llll}
\hline & $R P$ accessory pathway & $R P$ AV node & HV interval \\
\hline Procainamide & + & 0 & + \\
Quinidine & + & $-\leftrightarrow+$ & + \\
Ajmaline & + & 0 & + \\
Digitalis & - & + & 0 \\
Phenytoin & $\circ \leftrightarrow+$ & $-\leftrightarrow 0$ & 0 \\
Atropine & 0 & - & 0 \\
Propranolol & 0 & + & 0 \\
Lignocaine & $\circ \leftrightarrow+$ & - & 0 \\
Verapamil & $-\leftrightarrow 0$ & + & 0 \\
\end{tabular}

Abbreviation: $\mathbf{R P}=$ refractory period, $+=$ lengthens, $0=$ no effect, $-=$ shortens.

Based on data from Mandel et al. (1973), Rosen et al. (1972), Spurrell, Krikler, and Sowton (1974), Wellens and Durrer (1973a, 1974b), and Wellens (1975). 
etc.). If a circus movement tachycardia is present, treatment can be divided into a) prophylaxis of tachycardia and b) treatment during tachycardia. Prophylaxis of tachycardia consists of: $\mathrm{r}$ ) Prevention of the tachycardia-initiating premature beat and 2) reduction of the differences in length of the refractory period of the two AV pathways. Quinidine, preferably given as a long-acting preparation, is still the most effective drug for prevention of the premature beat. Digitalis can reduce the differences in length of the refractory period of the two pathways (Wellens and Durrer, 1973a). Drugs like quinidine or procainamide, by increasing the differences in length of the refractory period of the two pathways, can theoretically widen the range of premature beat intervals during which a tachycardia can be initiated (Wellens and Durrer, 1974b). In our experience, however, if tachycardias could still be initiated by premature beats following administration of these drugs, the zone of premature beat intervals capable of initiating tachycardia was observed to have shifted to longer premature beat intervals. Since the refractory period and the transmission time of the AV node are not affected, this suggests that premature beats given at intervals shorter than the ones followed by tachycardia meet refractory tissue in the accessory pathway at its ventricular insertion. If a circus movement tachycardia is present the arrhythmia will end if the product of the mean conduction velocity of the circulating wave and the mean refractory period of the different components of the tachycardia pathway exceeds the length of the tachycardia circuit (Mines, 1913). Most drugs have a twofold action. Thus, quinidine and procainamide prolong the refractory period in part of the tachycardia circuit but reduce its conduction velocity. As discussed elsewhere (Wellens, 1975), the final effect of a drug will depend upon the size and the electrophysiological properties of the different components of the tachycardia circuit. If in patients with recurrent attacks of circus movement tachycardia combinations of drugs have to be used, we like to combine a drug with prophylactic value and prolonging action on the refractory period of the accessory pathway (e.g. long acting quinidine) with a drug which prolongs the refractory period of the AV node (e.g. propranolol or verapamil). Under these circumstances it is frequently necessary to determine whether the accessory pathway is really a part of the tachycardia circuit (Wellens and Durrer, 1974d), since a drug which blocks the accessory pathway will immediately end a circus movement tachycardia, but will not interrupt a re-entry tachycardia in the AV node.

Procainamide is the most powerful drug as far as lengthening of the refractory period of the accessory pathway is concerned (Wellens and Durrer, 1974b). It is the drug of choice if atrial fibrillation or atrial flutter with high ventricular rates supervenes, unless serious haemodynamic problems call for immediate cardioversion. Digitalis can be a dangerous drug in patients with a short refractory period of their accessory pathway. It cannot be categorically stated, however, that the drug is contraindicated in WPW syndrome and atrial fibrillation (Wellens and Durrer, 1973a). It is our opinion that information on the length of the refractory period of the accessory pathway and the changes invoked by digitalis are required before deciding to use the drug. An important point which came out of these drug studies is the time dependency of the effect of drugs. Digitalis exerted its maximal effect $45 \mathrm{~min}$ utes after an intra-atrial administration. In most patients the effect of procainamide, quinidine, and ajmaline had disappeared one hour after administration by the same route. The short-lived effect of some of these drugs might explain unsatisfactory control of arrhythmias in patients with the WPW syndrome.

\section{Identification of high risk patients}

If an accessory pathway with a short refractory period is present in a patient with the WPW syndrome, atrial fibrillation or atrial flutter can become a life-threatening arrhythmia. Indeed ventricular fibrillation has been reported following the onset of atrial fibrillation (Dreifus et al., 197I). We have recently completed a study during which we compared the length of the refractory period of the accessory pathway (as determined by the single test stimulus method) with the ventricular frequency during spontaneous or electrically induced atrial fibrillation (Wellens and Durrer, 1974c). A good correlation was found between the length of the refractory period of the accessory pathway and the shortest $R R$ interval and mean ventricular rate during atrial fibrillation. This indicates that it is possible to identify those patients with WPW who are at risk if atrial fibrillation or atrial flutter supervene. At present we do not institute drug therapy in the asymptomatic patient with a short refractory period of his accessory pathway firstly because of the uncertainty regarding the natural history of the electrophysiological properties of the accessory pathway and of the incidence of sudden death in these patients and secondly because of the high incidence of side effects when employing the most potent drugs which lengthen the refractory period of the accessory pathway. We are following these patients carefully and intend to study the properties of their accessory pathway at regular intervals. 


\section{Postoperative evaluation}

In selected centres surgical therapy has been successfully performed in patients with the WPW syndrome whose tachycardias cannot be controlled by drug therapy. The necessity of identifying the tachycardia pathway before surgical intervention has already been discussed. In those patients who have circus movement tachycardias with the AV nodeHis bundle pathway incorporated in the circuit, section of the His bundle can result in relief from tachycardia (Dreifus et al., r968; Edmonds, Ellison, and Crews, 1969; Coumel et al., 1972; Dunaway et al., 1972; Wellens et al., 1974a). In these patients successful interruption of the His bundle can be demonstrated postoperatively not only by the inability to initiate circus movement tachycardia by a premature beat but also by showing that there are no changes in QRS configuration following atrial pacing at different sites and different frequencies. This is because ventricular excitation occurs only by way of the accessory pathway. Interruption of the pathway (Cobb et al., 1968; Wallace et al., I97 I, 1974; Fontaine et al., 1972; Wellens et al., 1974a) results in complete cure and is mandatory in patients with a short refractory period of their accessory pathway. After disappearance of pre-excitation, the patient should be re-evaluated postoperatively because, as discussed previously, in some patients the accessory pathway operative in AV during sinus rhythm or atrial pacing might not be the one used during tachycardia.

\section{References}

Anderson, R. H., Becker, A. E., Brechenmacher, C., Davies, M. J., and Rossi, L. (1975a). Ventricular pre-excitation. A proposed nomenclature for its substrates. European fournal of Cardiology. In the press.

Anderson, R. H., Becker, A. E., Davies, M. J., and Rossi, L. (1975b). The human atrioventricular junctional area. A morphologic study of the atrioventricular node. European fournal of Cardiology. In the press.

Anderson, R. H., Bouton, J., Burrow, C. T., and Smith, A. (1974). Sudden death in infancy: a study of cardiac specialized tissue. British Medical fournal, 2, 135.

Bissett, J. K., Thompson, A. J., de Soyza, N., and Murphy, M. L. (1973). Atrioventricular conduction in patients with short PR intervals and normal QRS complexes. British Heart fournal, 35, 123.

Boineau, J. P., Moore, E. N., Spear, J. F., and Sealy, W. C. (1973). Basis of clinical-ECG variations in right and left ventricular pre-excitation: a unitary concept of W.P.W. In Cardiac Arrhythmias, p. 421. Ed. by L. S. Dreifus and W. C. Likoff. Grune and Stratton, New York.

Brechenmacher, C., Laham, J., Iris, L. Gerbaux, A., and Lenégre, J. (1974). Etude histologique des voies anormales de conduction dans un syndrome de Wolff-ParkinsonWhite et dans un syndrome de Lown-Ganong-Levine. Archives des Maladies du Cour et des Vaisseaux, 67, 507.

Burchell, H. B., Frye, R. L., Anderson, M. W., and McGoon, D. C. (1967). Atrioventricular and ventriculoatrial excita- tion in Wolff-Parkinson-White syndrome (type B). Temporary ablation at surgery. Circulation, 36, 663 .

Burchell, H. B., and Sturm, R. E. (1967). Electroshock hazards. Circulation, 35, 227.

Caracta, A. R., Damato, A. N., Gallagher, J. J., Josephson, M. E., Varghese, P. J., Lau, S. H., and Westura, E. E. (1973). Electrophysiological studies in the syndrome short P-R interval, normal QRS complex. American fournal of Cardiology, 31, 245.

Castellanos, A., Jr., Castillo, C. A., Agha, A. S., and Tessler, M. (1971). His bundle electrograms in patients with short P-R intervals, narrow QRS complexes, and paroxysmal tachycardias. Circulation, 43, 667.

Castellanos, A., Jr., Chapunoff, E., Castillo, C. A., Maytin, O., and Lemberg, L. (1970). His bundle electrograms in two cases of Wolff-Parkinson-White (pre-excitation) syndrome. Circulation, 4I, 399.

Castellanos, A., Jr., Iyengar, R., Agha, A. S., and Castillo, C. A. (1972). Wenckebach phenomenon within the atria. British Heart fournal, 34, I 121.

Cobb, F. R., Blumenschien, S. D., Sealy, W. C., Boineau, J. P., Wagner, G. S., and Wallace, A. G. (1968). Successful surgical interruption of the bundle of Kent in a patient with Wolff-Parkinson-White syndrome. Circulation, 38, ror 8.

Coumel, Ph., and Attuel, P. (1974). Reciprocating tachycardia in overt and latent pre-excitation. European fournal of Cardiology, $1,423$.

Coumel, Ph., Waynberger, M., Fabiato, A., Slama, R., Aigueperse, J., and Bouvrain, G. (1972). Wolff-ParkinsonWhite syndrome. Problems in evaluation of multiple accessory pathways and surgical therapy. Circulation, 45, I216.

Denes, P., Wu, D., and Rosen, K. M. (1974). Demonstration of dual A-V pathways in a patient with Lown-GanongLevine syndrome. Chest, 65, 343

Dreifus, L. S., Haiat, R., Watanabe, Y., Arriaga, J., and Reitman, N. (197I). Ventricular fibrillation: a possible mechanism of sudden death in patients with WolffParkinson-White syndrome. Circulation, 43, 520.

Dreifus, L. S., Nichols, H., Morse, D., Watanabe, Y., and Truex, R. (1968). Control of recurrent tachycardia of Wolff-Parkinson-White syndrome by surgical ligature of the A-V bundle. Circulation, 38, ro3o.

Dunaway, M. C., King, S. B., Hatcher, C. R., and Logue, R. B. (1972). Disabling supraventricular tachycardia of Wolff-Parkinson-White syndrome (type A) controlled by surgical A-V block and a demand pacemaker after epicardial mapping studies. Circulation, 45, 522.

Durrer, D., and Roos, J. P. (1967). Epicardial excitation of the ventricles in a patient with Wolff-Parkinson-White syndrome (type B). Circulation, 35, 15.

Durrer, D., Schoo, L., Schuilenburg, R. M., and Wellens, H. J. J. (1967). Role of premature beats in the initiation and the termination of supraventricular tachycardia in the Wolff-Parkinson-White syndrome. Circulation, 36, 644.

Durrer, D., and Wellens, H. J. J. (1974). The Wolff-Parkinson-White syndrome, anno 1973. European fournal of Cardiology, r, 347.

Edmonds, J. H., Ellison, R. G., and Crews, T. L. (1969). Surgically induced atrioventricular block as treatment for recurrent atrial tachycardia in Wolff-Parkinson-White syndrome. Circulation, 39, Suppl. I, I05.

Fontaine, G., Guiraudon, G., Vachon, J., Bernard, J. P., Potier, J. C., Grosgogeat, G., and Cabrol, C. (I972). Section d'un faisceau de Kent dans un cas de syndrome de Wolff-Parkinson-White de type A-B. Archives des Maladies du Cour et des Vaisseaux, 65, 905.

Grolleau, R., Dufoix, R., Puech, P., and Latour, H. (1970). Les tachycardies par rythme réciproque dans le syndrome 
de Wolff-Parkinson-White. Archives des Maladies du Cour et des Vaisseaux, 63, 74.

Hecht, H. H., Kossmann, C. E., Childers, R. W., Langendorf, R., Lev, M., Rosen, K. M., Pruitt, R. D., Truex, R. C., Uhley, H. N., and Watt, T. B., Jr. (1973). Atrioventricular and intraventricular conduction. Revised nomenclature and concepts. American fournal of Cardiology, 31, 232.

Holzmann, M., and Scherf, D. (1932). Uber Electrocardiogramme mit verkürzter Vorhof-Kammer-Distanz und positiven P-Zacken. Zeitschrift fur klinische Medizin, 121, 404.

James, T. N. (1963). The connecting pathways between the sinus node and A-V node and between the right and left atrium in the human heart. American Heart fournal, 66, 498.

Josephson, M. E., Caracta, A. R., and Lau, S. H. (1974). Alternating type $\mathrm{A}$ and type $\mathrm{B}$ Wolff-Parkinson-White syndrome. American Heart fournal, 87, 363.

Lev, M., Leffler, W. B., Langendorf, R., and Pick, A. (1966). Anatomic findings in a case of ventricular pre-excitation (W.P.W.) terminating in complete atrioventricular block. Circulation, 34, 718.

Mahaim, I., and Winston, M. R. (194I). Recherches d'anatomie comparée et de pathologie expérimentale sur les connexions hautes du faisceau de His-Tawara. Cardiologia, $5,189$.

Mandel, W. J., Danzig, R., and Hayakawa, H. (I97I). LownGanong-Levine syndrome. A study using His bundle electrograms. Circulation, 44, 696.

Mandel, W. J., Laks, M., Obayaski, K., and Clifton, J. (1973). Electrophysiologic features of the W.P.W. syndrome: modification by procainamide (abstract). Circulation, 48, Suppl. 4, 195.

Mines, G. R. (1913). On dynamic equilibrium in cardiac muscle. Fournal of Physiology, 46, 23.

Narula, O. S., Runge, M., and Samet, P. (1972). Seconddegree Wenckebach type AV block due to block within the atrium. British Heart fournal, 34, I 127.

Roelandt, J., Schamroth, L., Draulans, J., and Hugenholtz, P. G. (1973). Functional characteristics of the WolffParkinson-White bypass. A study of six patients with His bundle electrograms. American Heart fournal, 85, 260.

Rosen, K. M., Barwolf, C., Ehsani, A., and Rahimtoola, S. H. (1972). Effects of lidocaine and propranolol on the normal and anomalous pathways with pre-excitation. American Fournal of Cardiology, 30, 801.

Rosenbaum, F. F., Hecht, H. H., Wilson, F. N., and Johnston, F. D. (1945). Potential variations of the thorax and the esophagus in anomalous atrioventricular excitation (Wolff-Parkinson-White syndrome). American Heart fournal, 29, 281.

Scherlag, B. J., Lau, S. H., Helfant, R. H., Berkowitz, W. D., Stein, E., and Damato, A. N. (1969). Catheter technique for recording His bundle activity in man. Circulation, 39, I3.

Slama, R., Coumel, Ph., and Bouvrain, X. (1973). Les syndromes de Wolff-Parkinson-White de type $\mathrm{A}$ inapparents ou latents en rhythme sinusal. Archives des Maladies $d u$ Cour et des Vaisseaux, 66, 639.

Spurrell, R. A. J., Krikler, D. M., and Sowton, E. (1974). Effects of verapamil on electrophysiological properties of anomalous atrioventricular connection in Wolff-ParkinsonWhite syndrome. British Heart fournal, 36, 256.

Spurrell, R. A. J., Krikler, D. M., and Sowton, E. (1975). Problems concerning assessment of anatomical site of accessory pathway in Wolff-Parkinson-White syndrome. British Heart fournal, 37, 127.

Starmer, C. F., Whalen, R. E., and McIntosh, H. D. (1964). Hazards of electrical shock in cardiology. American fournal of Cardiology, 14, 537.
Svenson, R. H., Gallagher, J. J., Sealy, W. C., and Wallace, A. G. (1974). An electrophysiologic approach to the surgical treatment of the Wolff-Parkinson-White syndrome: report of two cases utilizing catheter recording and epicardial mapping techniques. Circulation, 49, 799.

Touboul, P., Tessier, Y., Magrina, J., Clément, C., and Delahaye, J. P. (1972). His bundle recording and electrical stimulation of atria in patients with Wolff-ParkinsonWhite syndrome type A. British Heart Journal, 34, 623 .

Wallace, A. G., Boineau, J. P., Davidson, R. M., and Sealy, W. C. (I97I). Wolff-Parkinson-White syndrome. A new look. American fournal of Cardiology, 28, 509.

Wallace, A. G., Sealy, W. C., Gallagher, J. J., Svenson, R. H., Strauss, H. C., and Kasell, J. (1974). Surgical correction of anomalous left ventricular pre-excitation: WolffParkinson-White (type A). Circulation, 49, 206.

Wellens, H. J. J. (197I). Electrical Stimulation of the Heart in the Study and Treatment of Tachycardias. H. E. Stenfert Kroese N.V., Leiden.

Wellens, H. J. J. (1974). Effect of drugs on Wolff-ParkinsonWhite syndrome and its therapy. In Clinical His Bundle Electrography. Ed. by O. Narula. F. A. Davis, Philadelphia. In the press.

Wellens, H. J. J., and Durrer, D. (I973a). Effect of digitalis on atrioventricular conduction and circus-movement tachycardias in patients with Wolff-Parkinson-White syndrome. Circulation. 47, 1229.

Wellens, H. J. J., and Durrer, D. (1973b). Combined conduction disturbances in two AV pathways in patients with Wolff-Parkinson-White syndrome. European fournal of Cardiology, 1, 23.

Wellens, H. J. J., and Durrer, D. (1974a). Patterns of ventriculo-atrial conduction in the Wolff-Parkinson-White syndrome. Circulation, 49, 22.

Wellens, H. J. J., and Durrer, D. (1974b). Effect of procaineamide, quinidine and ajmaline on the Wolff-ParkinsonWhite syndrome. Circulation, 50, I14.

Wellens, H. J. J., and Durrer, D. (I974C). Relation between refractory period of the accessory pathway and ventricular frequency during atrial fibrillation in patients with WolffParkinson-White syndrome (abstract). American fournal of Cardiology, 33, 178.

Wellens, H. J. J., and Durrer, D. (1974d). Pathway of tachycardia in Wolff-Parkinson-White syndrome. Circulation, 50, Suppl. 3, 58.!

Wellens, H. J. J., Janse, M. J., van Dam, R., Th., van Capelle, F. J. L., Meijne, N. G., Mellink, H. M., and Durrer, D. (1974a). Epicardial mapping and surgical treatment in Wolff-Parkinson-White syndrome type A. American Heart fournal, 86, 69.

Wellens, H. J. J., Lie, K. I., and Durrer, D. (1974b). Further observations on ventricular tachycardia as studied by electrical stimulation of the heart. Circulation, 49, 647.

Wellens, H. J. J., Schuilenburg, R. M., and Durrer, D. (197I). Electrical stimulation of the heart in patients with WolffParkinson-White syndrome, type A. Circulation, 43, 99.

Wolferth, C. C., and Wood, F. C. (1933). The mechanism of production of short P-R intervals and prolonged $Q R S$ complexes in ptients with presumably undamaged hearts: hypothesis of an accessory pathway of auriculo-ventricular conduction (bundle of Kent). American Heart fournal, 8, 297.

Zipes, D. P., DeJoseph, R. L., and Rothbaum, D. A. (1974). Unusual properties of accessory pathways. Circulation, 49, 1200.

Requests for reprints to Professor Hein J. J. Wellens, University Department of Cardiology, Wilhelmina Gasthuis, Amsterdam, The Netherlands. 